\title{
Design of a Combustion Chamber Suitable for Diesel/Natural Gas Dual Fuel Engine
}

\author{
Zhou Yang ${ }^{1, a}$, Zhongshu Wang ${ }^{2, b}$, Hengyi Yuan ${ }^{1, c}$, and Hongzhi Wang ${ }^{1, d}$ \\ ${ }^{1}$ School of Jilin Engineering Normal University, Changchun 130000, China \\ ${ }^{2}$ School of Jilin University, Changchun 130025, China

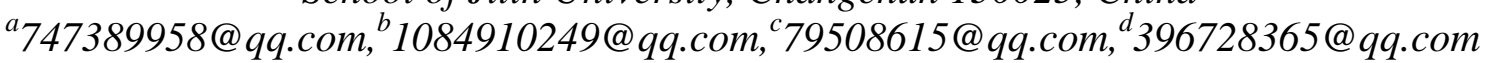

Keywords: diesel / natural gas dual fuel; combustion chamber; engine

\begin{abstract}
Based on the common issues for diesel / natural gas dual fuel engine existing in the key technologies, the main purpose of this research is to solve the low thermal efficiency and high $\mathrm{CH} 4$ emissions under low load conditions. In order to improve the performance of economic and reduce $\mathrm{CH} 4$ emissions, the combustion chamber has been optimally designed to enhance cylinder turbulent flow and improve the mixed gas combustion. The numerical simulation platform is established by using the commercial software STAR-CD and its validity is verified. A new type of combustion chamber has been designed to improve the flow in the cylinder and the combustion rate through analyzing the variation of micro combustion parameters in the cylinder under the original condition $(1335 \mathrm{r} / \mathrm{min}, 218 \mathrm{~N} \bullet \mathrm{m})$. The results show that compared to the original engine, the new combustion chamber can effectively enhance the turbulent flow in cylinder, the maximum explosion pressure increases by nearly $25 \%$ and the natural gas residual rate reduces from $28.6 \%$ to $0.5 \%$. The optimal design method has improved the combustion quality and the economy and emissions performances greatly.
\end{abstract}

\section{Introduction}

Environmental problems and resource problems are two major problems in today's social development. Therefore, the State Council issued the "National Environmental Protection "12th Five-Year" Plan", which clearly pointed out that "we should strive to reduce the emission of new pollutants, rationally control the total energy consumption, and promote the development of nonfossil energy”. Under this trend, natural gas engines have been widely used for their rich resources and friendly emissions [1,2,3,4,5]. According to the current use of the natural gas engine, it is mainly divided into two categories: natural gas spark ignition and diesel / natural gas dual fuel compression ignition type. Compared with the natural gas spark ignition engine, the diesel / natural gas dual fuel engine has attracted more and more attention because it has high thermal efficiency and its dual fuel mode is conductive to long-distance transportation [6].

However, there are still some problems in diesel / natural gas dual fuel engine at present. The most prominent problem is that the combustion is not complete at low load, and a lot of natural gas is discharged out of the cylinder without combustion, leading to higher $\mathrm{CH}_{4}$ emissions. This phenomenon is more serious under the high substitution rate $[7,8,9]$. Studies at home and abroad 
show that the shape of the combustion chamber has an important influence on the combustion process[10]. The diesel / natural gas dual fuel engines on the market are mostly converted from diesel engines or gasoline engines, and the most common is the reentrant $\omega$ - shaped combustion chamber of the original diesel engine. The diesel / natural gas dual fuel engine has both diffusion combustion and premixed combustion, which has characteristics of both spark ignition engine and compression ignition engine. Therefore, the combustion chamber, which is only suitable for gasoline engines and diesel engines, is obviously not the best choice for dual fuel engines, so it is particularly necessary to redesign the combustion chamber.

In this study, the numerical simulation was carried out for original combustion chamber and designed combustion chamber by using the commercial computing software STAR-CD to explore the causes of incomplete combustion of the original combustion chamber and the incomplete combustion position. A combustion chamber was redesigned in order to improve the incomplete combustion, increase thermal efficiency and explore the influence of the shape of combustion chamber on the combustion process of the diesel/natural gas dual fuel engine.

\section{Engine Parameters}

The diesel / natural gas dual fuel engine used in the test was developed on the basis of the original 6DL diesel engine. The natural gas used the intake-port multipoint injection, while the diesel used the direct injection in cylinder. The engine bench is shown in Fig. 1, and the basic technical parameters are shown in Table 1.

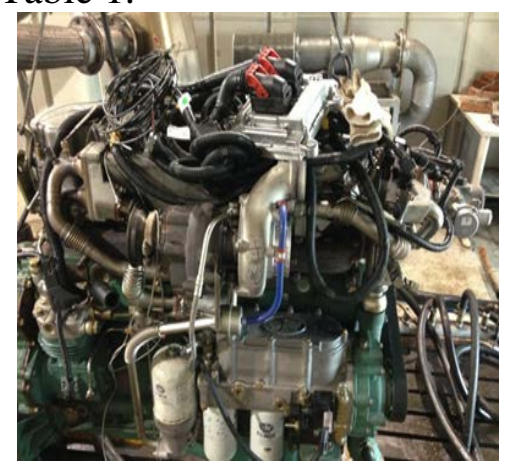

Figure 1. Diesel / natural gas dual fuel engine test bench.

Table 1. Technical parameters of diesel / natural gas dual fuel engine.

\begin{tabular}{cccccc}
\hline Type & $\begin{array}{c}\text { Cylinder } \\
\text { diameter×stroke }\end{array}$ & $\begin{array}{c}\text { Total } \\
\text { displacement }\end{array}$ & $\begin{array}{c}\text { Compression } \\
\text { ratio }\end{array}$ & $\begin{array}{c}\text { Fuel } \\
\text { injection } \\
\text { system }\end{array}$ & $\begin{array}{c}\text { rated } \\
\text { power }\end{array}$ \\
\hline $\begin{array}{c}\text { In-line six-cylinder } \\
\text { water-cooled four } \\
\text { stroke turbocharging } \\
\text { inter-cooling type }\end{array}$ & $112 \times 145 \mathrm{~mm}$ & $8.6 \mathrm{~L}$ & 17.2 & $\begin{array}{c}\text { High } \\
\text { pressure } \\
\text { common } \\
\text { rail }\end{array}$ & $258 \mathrm{~kW}$ \\
\hline
\end{tabular}

\section{The Establishment of the Model}

\subsection{Computing Grid}

The commercial computing software STAR-CD is used for combustion simulation, and the computing grid is shown in Fig.2.The number of the grid is 299284. 


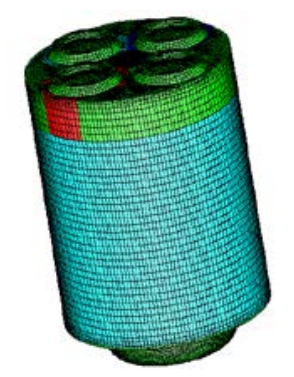

Figure 2. Computing grid

\subsection{Model and Algorithm Selection}

The RNG k- $\varepsilon$ turbulence model, Reitz/Diwakar droplet breakup model and Bai wall impingement model were adopted in the simulation calculation. The ECFM-3Z combustion model was used. The system description of the combustion process of the combustion model shows that all the combustion modes can be displayed simultaneously in this model, which makes the model applicable to all types of combustion devices without having to conjecture the type of combustion that may be encountered. The PISO algorithm was adopted in simulation.

\subsection{Simulation Calculation Conditions}

The initial pressure was obtained by the indicator diagram obtained by the experiment. The temperature of the air in the cylinder was calculated by the initial temperature based on the flow measured by the air flow meter. The air quality error was within $10 \%$, and the initial temperature was obtained by the STAR-CD software. The swirl ratio used in the simulation was 1.2, and the swirl speed Omega was used to realize. When the working condition was $1335 \mathrm{r} / \mathrm{min}$, the swirl ratio was $1602 \mathrm{r} / \mathrm{min}$. The wall is adiabatic. In order to improve the accuracy of this study, the starting angle was selected at the moment of the intake valve just closed, that was the $120^{\circ} \mathrm{CA}$ before top dead center(TDC), and the end angle was selected at the end of combustion, that was $70^{\circ} \mathrm{CA}$ after TDC. $360^{\circ} \mathrm{CA}$ was the compression top dead center, and the fuel injection began $7^{\circ} \mathrm{CA}$ before the TDC.

\subsection{Model Verification}

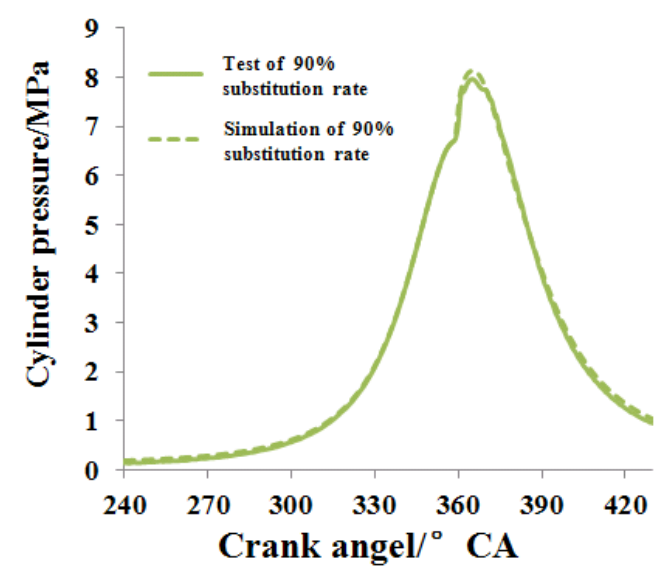

(a) The change relationship of cylinder pressure curve with crank angle

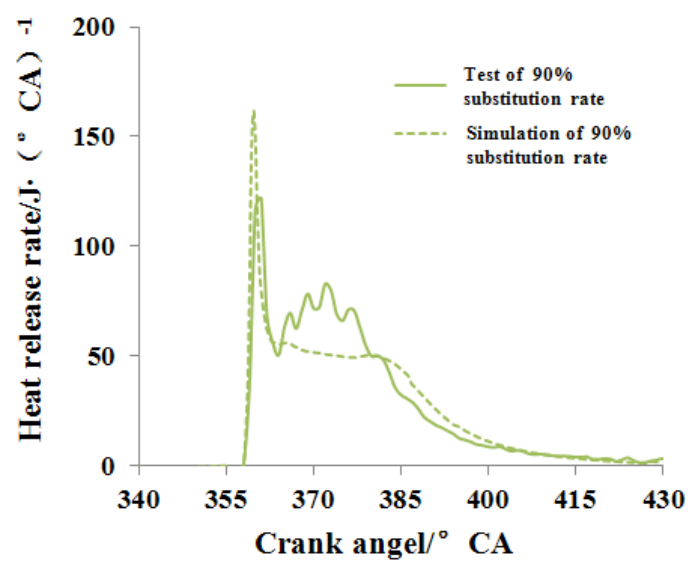

(b)The change relationship of heat release rate curve with crank angle

Figure 3. Simulation verification 
In order to verify the accuracy of the selected model, the simulation and test results were compared at $1335 \mathrm{r} / \mathrm{min}, 218 \mathrm{~N} \cdot \mathrm{m}$ and the substitution rate of $90 \%$. As shown in Fig.3(a) and Fig.3(b), it can be seen from the cylinder pressure curve and the heat release rate curve that the test and simulation coincide well in peak value and phase. Therefore, the simulation results agree well with the experimental results, so the selected models and calculation methods are reasonable.

\section{Influence Law of Shape of Combustion Chamber}

In this study, the original $\omega$-shaped combustion chamber (Fig.4(a) shows) and the self-designed eight-petal dumbbell-shaped combustion chamber (Fig.4(b) shows) were used to carry out the numerical simulation of the combustion chamber shape on the combustion process of diesel/natural gas engine. The simulated working condition point selected the working condition with $1335 \mathrm{r} / \mathrm{min}$ which is prone to incomplete combustion, $25 \%$ load of the original diesel engine and $90 \%$ substitution rate. For the simulation calculation, in addition to the different shape of the combustion chamber, all other conditions were consistent.

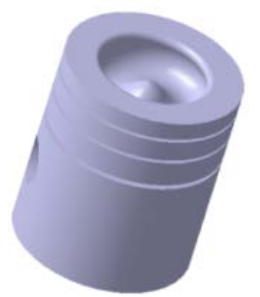

(a)The original $\omega$ - shaped combustion chamber

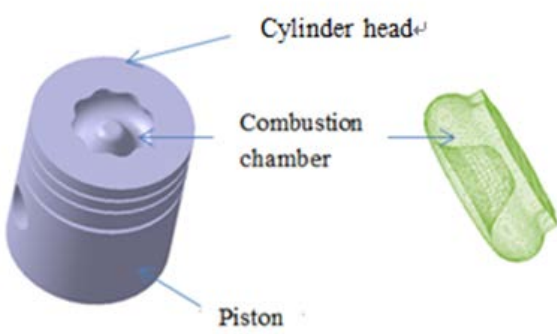

(b)The eight-petal dumbbell-shaped combustion chamber

Figure 4. Structure of combustion chamber

\subsection{Analysis of Macro Simulation}

Fig. 5 shows the simulation results of the influence of the combustion chamber shape on the parameters in the cylinder. It can be seen that the shape of the combustion chamber has an important effect on the combustion process of a diesel / natural gas dual fuel engine.

As Fig.5(a) shows, at the beginning of the combustion after the TDC, the cylinder pressure of the original combustion chamber is slightly higher and the ignition delay period is short. However, after that, the cylinder pressure of the eight-petal dumbbell-shaped combustion chamber is higher than that of the original combustion chamber, especially during the emergency combustion period. The eight-petal dumbbell-shaped combustion chamber has good fixed capacity and the maximum explosion pressure increases by $25 \%$, so the power and economy performance is greatly improved. As Fig.5(b) shows that the heat release rate of the eight-petal dumbbell-shaped combustion chamber is faster, the combustion speed is higher than that of the original combustion chamber, so the eightpetal dumbbell-shaped combustion chamber is more suitable for diesel / natural gas dual fuel engine. As Fig.5(c) shows, the average temperature curve in the cylinder also verifies this trend. As Fig.5(d) shows, the residual percentage of fuel curve shows that the residual fuel in the cylinder of the eightpetal dumbbell-shaped combustion chamber is lower than that in the original combustion chamber, especially the natural gas. It can be seen from the figure that the combustion of natural gas basically depends on the ignition of diesel oil, and the burning rate of natural gas slows down when the diesel combustion ends. Due to the long ignition delay period, the amount of diesel accumulated in the eight-petal dumbbell-shaped combustion chamber during the premixed period is large, and more natural gas is ignited. Therefore, the residual percentage of natural gas of the eight-petal dumbbell- 
shaped combustion chamber reduces from $28.6 \%$ to $0.5 \%$, comparing with the original engine, overcoming the phenomenon of incomplete combustion of the original combustion chamber and improving the utilization of natural gas.
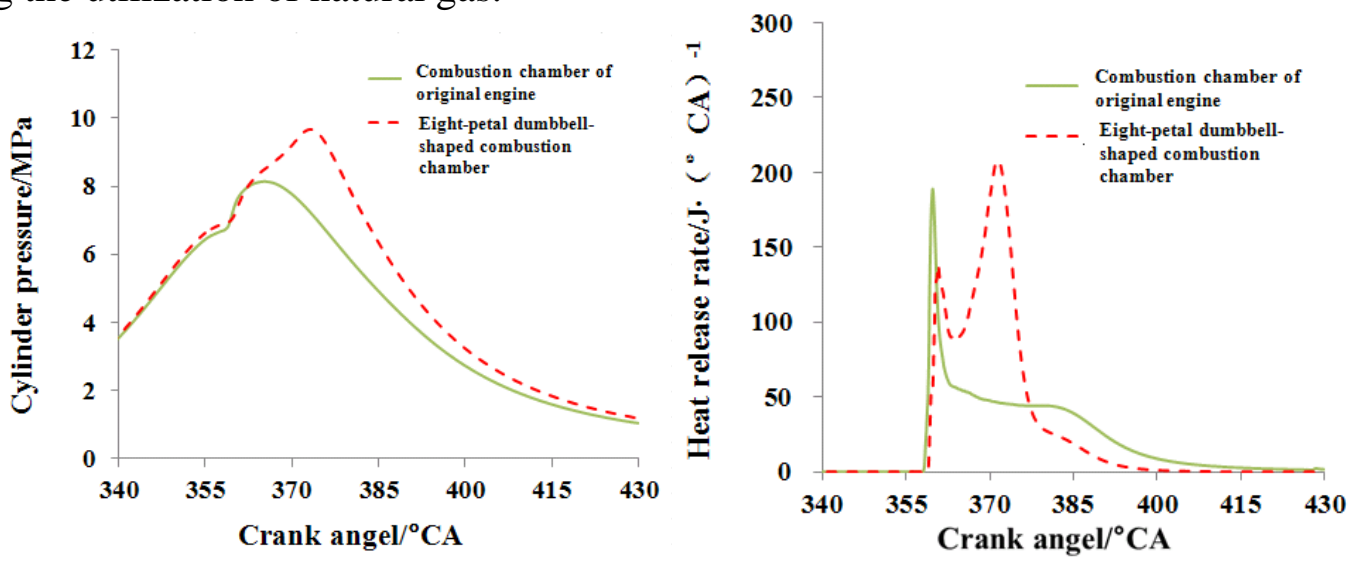

(a)Cylinder pressure

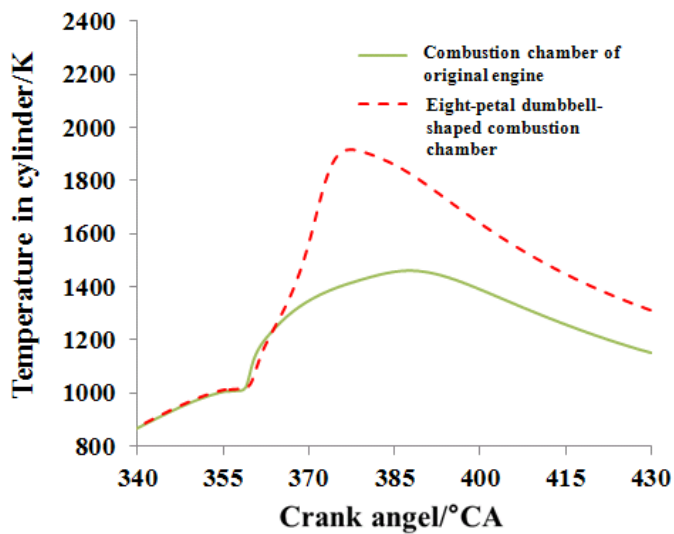

(b)Heat release rate

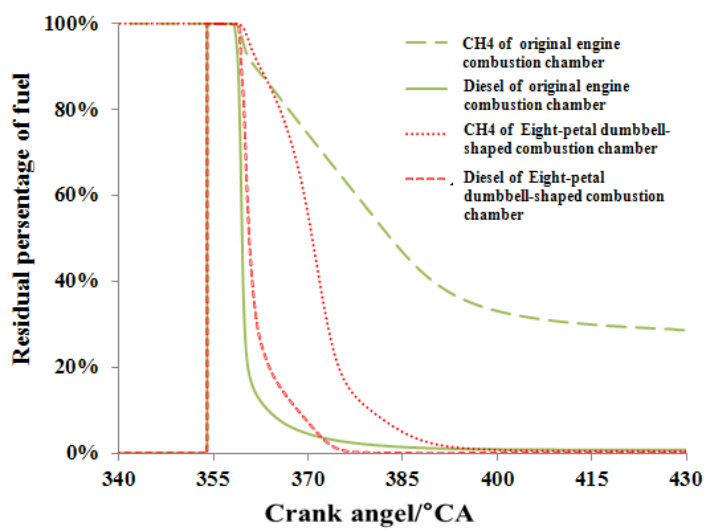

(c)Temperature in cylinder

(d)Residual percentage of fuel

Figure 5. The influence of the shape of the combustion chamber on the parameters in the cylinder

\subsection{Analysis of Micro Simulation}

Analysis of Turbulent Kinetic Energy Field in Cylinder. The distribution of turbulent kinetic energy in the cylinders of the two combustion chambers is shown in Fig. 6. At the beginning of compression stroke, the shape of combustion chamber has little effect on turbulent kinetic energy in cylinder, and the change rule of the turbulent kinetic energy in the cylinders of two combustion chambers is similar. As the crank angle increases, the piston moves upward, the volume of cylinder decreases, the turbulence intensity decreases, and the influence of combustion chamber shape on the turbulent kinetic energy of cylinder increases.

As Fig.6(a) shows near the TDC, the turbulent kinetic energy of the eight-petal dumbbell-shaped combustion chamber is widely distributed, and the average turbulent kinetic energy is larger than that of the original combustion chamber. The larger turbulent kinetic energy is due to the swirl and squish. There is basically no turbulent kinetic energy at the bottom of the original combustion chamber. That is to say, the original combustion chamber contributes to the stability of the flame kernel during the initial stage of ignition.

As Fig.6(b)(c)(d) shows, during the combustion process, the high turbulent kinetic energy is beneficial to the full mixing of diesel and surrounding mixed gas to make the diesel distribution more uniform. The turbulent kinetic energy in the cylinder of eight-petal dumbbell-shaped 
combustion chamber is widely distributed, and keeps a high level for a long time, which is mainly caused by the side angle action of the eight petals and the strong swirl caused by changes in upper eight-petal and lower dumbbell-shaped sections. The turbulent kinetic energy of the original combustion chamber is small, which is not conducive to the mixing of diesel and surrounding mixed gas.

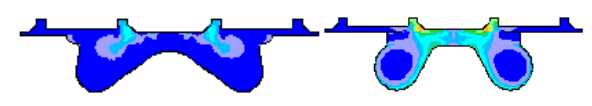

(a)Top dead center

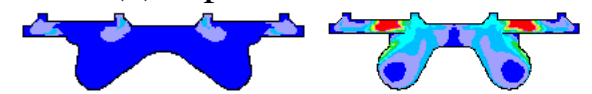

(b) $15^{\circ} \mathrm{CA}$ after the top dead center

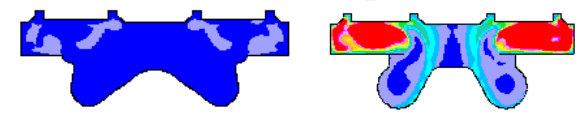

(c) $30^{\circ} \mathrm{CA}$ after the top dead center
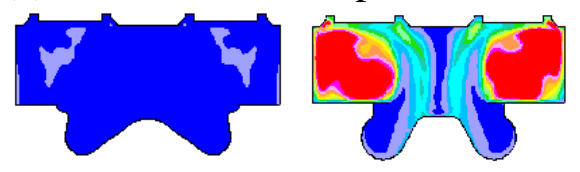

(d) $50^{\circ} \mathrm{CA}$ after the top dead center

$$
\mathrm{m}^{2} / \mathrm{s}^{2}
$$

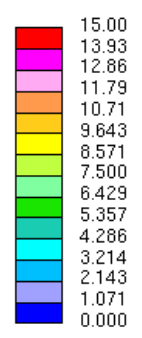

000

Figure 6. The distribution of turbulent kinetic energy field in cylinders of two kinds of combustion chambers

Analysis of Diesel Concentration Field in Cylinder. Fig. 7 shows the change rule of the diesel concentration field with the crank angle in the two combustion chambers. It can be seen from the figure that the shape of the diesel oil beam is different due to the influence of the shape of combustion chamber causing the flow field in cylinder in the process of diesel injection. As Fig.7(a)(b) shows, the piston moves up, due to the weak flow in the original combustion chamber, the diesel oil moves toward the cylinder wall by inertia. The turbulent kinetic energy in the combustion chamber upper cylinder is small, which is conductive to the formation of a stable flame kernel. Therefore, during the process of moving to the cylinder wall, ignition begins, without touching the wall. There is a large dumbbell shaped convex in the middle of the eight-petal dumbbell-shaped combustion chamber, which has the effect of diversion, so the diesel oil spreads along the boss wall into the combustion chamber. The turbulent kinetic energy near the convex is large, which is unfavorable for the formation of stable flame kernel. Therefore, the ignition delay period of the eight-petal dumbbell-shaped combustion chamber is longer than that of the original one. Ignition begins on the convex side wall in the eight-petal dumbbell-shaped combustion chamber. There is a great difference between the location of the two ignition points.

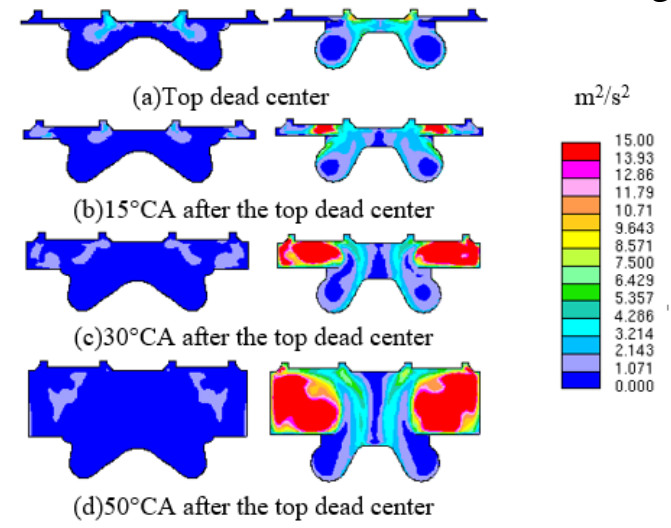

Figure 7. Distribution of diesel concentration field in cylinders of two combustion chambers 
As Fig.7(c)the piston descends, the turbulent kinetic energy of the bottom of the original combustion chamber is small and the flow is weak, and the diesel oil does not spread to the bottom of the combustion chamber. The turbulent kinetic energy of the eight-petal dumbbell-shaped combustion chamber is widely distributed, and the turbulent kinetic energy of the combustion chamber is larger in the process of the diffusion of the diesel flame kernel, which is beneficial to the full mixing of diesel and mixed gas. The distribution of diesel oil is uniform, and the diesel combustion is more complete, so more natural gas has been ignited.

\section{Conclusion}

In this paper, the numerical simulation is carried out for the electronically controlled diesel/natural gas duel fuel engine to study the effects of two combustion chambers on the combustion of the engine. The following conclusions are obtained:

The simulation results agree well with the experimental results, so the selected models and calculation methods are reasonable.

From the macro point of view, after the change of the shape of the combustion chamber, the natural gas residual rate reduces from $28.6 \%$ to $0.5 \%$, which overcomes the incomplete combustion of the original combustion chamber and reduces the $\mathrm{CH} 4$ emission at the same time. Eight-petal dumbbell-shaped combustion chamber has good fixed capacity and the maximum explosion pressure increases by $25 \%$, so the power and economy performance is greatly improved.

From the micro point of view, the residual gas rate of the original combustion chamber is large and the $\mathrm{CH} 4$ emission is high because on the one hand, the distribution of the diesel ignition point of the original combustion chamber is not reasonable, on the other hand, the turbulent kinetic energy is small, which is not conducive to the ignition of the diesel and the mixing with surrounding air and the diffusion combustion, so the combustion of natural gas is incomplete. The eight-petal dumbbell-shaped combustion chamber is beneficial because the larger turbulent kinetic energy is conducive to the full mixing of diesel and mixed gas, so that the ignited diesel fuel is widely distributed, which is beneficial to diesel combustion so as to ignite natural gas.

\section{Acknowledgements}

This work was financially supported by the National Natural Fund (50906033), the Program for Innovation Research Team of Jilin Engineering Normal University and the School Teaching Technology Project of Jilin Engineering Normal University, Development and Production of Automobile Engine Structure Microcourse. Communication author is Hengyi Yuan, 79508615@qq.com.

\section{References}

[1] Chunde Yao, Hanjun Xu, Development and research status of vehicle fuel and its future prospect, J. Journal of automotive safety and energy conservation, 2, (2011) 101-110.

[2] Zhongshu Wang, Zhongchang Liu, Huili Dou et al, Study on combustion process of spark ignition CNG engine, J. Vehicle engine, 6(2007) 5-11.

[3] Henian Qin, Pengyu Zheng, Development status and Prospect of vehicle fuel gas, J. Petroleum technology, 5 (2012) $8-11$.

[4] Shengdun Zhao, Ningyu Gui, Minchao C ui, et al, Discussion on automotive natural gas engine and its key technologies, J. Automotive practical technology, 2(2015): 1-3.

[5] Qi Shao, Ning Wang, Lihe Yan, Application research progress of natural gas engine, J. Modern chemical industry, 7(2015) 1595-1601.

[6] Rolf D. Reitz, Ganesh Duraisamy, Review of high efficiency and clean reactivity controlled compression ignition (RCCI) combustion in internal combustion engines, J. Progress in Energy and Combustion Science, 46(2015):12-71. 
[7] Antonio Paolo Carlucci, Domenico Laforgia, Roberto Saracino,et al, Study of Combustion Development in Methane-Diesel Dual Fuel Engines, Based on the Analysis of In-Cylinder Luminance[C]// SAE paper. Detroit, Michigan, 2010: 2010-01-1297.

[8] Nwafor OMI. Combustion characteristics of dual-fuel diesel engine using pilot injection ignition. Institution of Engineers Journal April 2003, 84:22-35.

[9] Selim MYE, Effect of exhaust gas recirculation on some combustion characteristics of dual fuel engine, J. Energy Conversionand Management, 44(2003)707-721.

[10] Teresa Donateo, Luciano Strafella, Domenico Laforgia. Effect of the Shape of the Combustion Chamber on Dual Fuel Combustion.SAE paper 2013; 2013-24-0115. 